\title{
TEORIAS DA JUSTIÇA PÓS-RAWLS: UMA ANÁLISE COMPARADA ENTRE $O$ MODELO IGUALITÁRIO DE RONALD DWORKIN E AMARTYA SEN
}

\author{
POST-RAWLS JUSTICE THEORIES: A COMPARATIVE ANALYSIS BETWEEN THE EGALITARIAN \\ MODEL OF RONALD DWORKIN AND AMARTYA SEN
}

Thais Cristina Alves Costa*

\begin{abstract}
RESUMO
O presente texto trata da comparação entre dois modelos de justiça influenciados pelas ideias políticas de Jonh Rawls que, apesar da importância da sua teoria enquanto justiça, ela possui um caráter insuficientemente igualitário. Dois outros filósofos políticos tentarão aperfeiçoar essa proposta com novas perspectivas, a saber: a igualdade de recursos de Ronald Dworkin e a igualdade de capacidades de Amartya Sen. Com o intuito de apresentar as principais semelhanças e diferenças desses dois sistemas em relação à proposta rawlsiana, utilizaremos como fio condutor as obras Sovereign Virtue: the Theory and Practice of Equality de Dworkin e Development as freedom de Sen. Através desse comparado será possível apreender como esses dois filósofos conseguiram aperfeiçoar a proposta igualitária engendrada por John Rawls. Tenta-se, portanto, de analisar se os dois filósofos foram ou não felizes em suas empreitadas e, para tal, estabeleceremos uma comparação entre as principais proposições deles em relação à teoria originária de Rawls.

PALAVRAS-CHAVE: Teorias da justiça. Recursos. Capacidade. Bens primários. Igualdade.
\end{abstract}

\begin{abstract}
It is the comparison between two models of justice influenced by the political ideas of John Rawls, namely: the equal resources of Ronald Dworkin and the equal capabilities of Amartya Sen. In order to present the main similarities and differences of these two systems with the Rawlsian's proposal, we will use as a guiding line the works Sovereign Virtue: the Theory and Practice of Equality of Dworkin, and Development as freedom of Sen. Through this comparison it will be possible to apprehend how these two philosophers have succeeded in perfecting the egalitarian proposal engendered by John Rawls. It is therefore tried to analyze whether the two philosophers were happy in their works and to do so we will establish a comparison between their main propositions in relation to the original theory of Rawls KEYWORDS: theories of justice. Resources. Capacity. Primary goods. Equality.
\end{abstract}

\footnotetext{
* Doutoranda em Filosofia pela Universidade Federal de Pelotas. E-mail: thaisfilosofias @ bol.com.br.
} 


\section{INTRODUÇÃO}

John Rawls (1921-2002) foi o grande precursor da filosofia política de seu tempo. Através de suas obras A theory of justice, justice as fairness e Political liberalism demonstrou a necessidade de uma nova forma de pensar a justiça. Seu pensamento baseia-se na premissa de que as instituições básicas de uma sociedade somente poderão ser consideradas justas quando as pessoas conseguirem seguir o plano de vida que desejam. Para isso, essas instituições devem garantir a mesma igualdade a todos, enquanto ponto de partida. Em outras palavras, o Estado deve garantir a toda sociedade as mesmas oportunidades iniciais, ou seja, o conjunto igual de bens primários e, a partir disso, cada um escolhe como quer viver. No intuito de garantir essa igualdade, certas desigualdades podem ser permitidas.

Estes são os princípios fundamentais rawlsianos: os princípios da igual liberdade (equal liberty principle) e o princípio da diferença (difference principles) ${ }^{1}$. O primeiro consiste na ideia de que "cada pessoa tem um direito igual a um sistema plenamente adequado de direitos e liberdades iguais, sistema que deve ser compatível com um sistema similar a todos" (RAWLS, 2011, p. 06). Em outras palavras, é o princípio das igualdades básicas, tais como participação política, direito ao voto, liberdade de consciência e pensamento, de não sofrer agressão física e psicológica, entre outras. Essas liberdades possuem regras de prioridades, ou seja, uma pode sobrepesar a outra se a motivação for o fortalecimento da ampla liberdade para todos.

O primeiro princípio parte do pressuposto de que as pessoas escolheram os princípios de justiça que seguem a partir do dispositivo procedimental da posição original. Nessa condição idealizada, as partes que representam os cidadãos na sociedade real são livres, iguais e racionais para fazerem as escolhas dos princípios que serão aplicados à estrutura básica da sociedade. Ainda, na posição original todos se encontram em uma condição simétrica e imparcial, por isso, todos têm liberdades que não são passíveis de negociação e podem ser restringidas apenas em casos fortuitos nos quais é, necessariamente, diminuída para todos. Por

\footnotetext{
${ }^{1}$ Cito os princípios: "a. Cada pessoa tem um direito igual a um sistema plenamente adequado de direitos e liberdades iguais, sistema que deve ser compatível com um sistema similar a todos; $b$. As desigualdades sociais e econômicas devem satisfazer a duas condições. Primeiro, devem estar associadas a cargos e a posições abertos a todos, em condições de uma equitativa igualdade de oportunidades; e, segundo, devem proporcionar o maior benefício aos membros menos favorecidos da sociedade”. (RAWLS, 2011, p.06).
} 
Artigo: Teorias da justiça pós-Rawls: uma análise comparada entre o modelo igualitário de Ronald Dworkin e Amartya Sen

exemplo, na ocorrência de catástrofes, ou em casos de restrições de liberdades desiguais, quando uma pessoa fica absolutamente ou relativamente incapaz.

Por sua vez, o segundo princípio consiste na diferença permitida dentro de um sistema, ou seja, as diferenças de cargos, escolhas e oportunidades que são aceitáveis na sociedade. Este princípio diz respeito às condições de desigualdades sociais. Nesse caso, o desafio é responder à seguinte questão: como determinar qual é a diferença aceitável? A resposta de Rawls é que, "em primeiro lugar, devem estar vinculadas as posições e cargos abertos a todos em condições de igualdade equitativa de oportunidades" (RAWLS, 2002, p. 06). Em outras palavras, todos devem ter o igual acesso a oportunidade, o que não significa que, necessariamente, todos desejarão o mesmo cargo. Sendo assim, o que importa é que todos tenham a mesma condição de acesso. Esses princípios compõem a estrutura da justiça distributiva rawlsiana, a qual deve conter como requisitos básicos universalidade, publicidade, finalidade, entre outros.

Entretanto, apesar da importância da teoria de Rawls enquanto justiça, ela possui um caráter insuficientemente igualitário. Nessa perspectiva, dois outros filósofos políticos tentarão aperfeiçoar essa proposta, são eles: Ronald Dworkin e Amartya Sen. Tentaremos analisar se os dois filósofos foram ou não felizes em suas empreitadas. Para tal, demonstraremos as principais similitudes e diferenças do pensamento desses dois filósofos em relação à teoria originária de Rawls.

\section{A IGUALDADE DE RECURSOS COMO CONDIÇÃO PARA O IGUALITARISMO LIBERAL DWORKINIANO}

Para o filósofo norte-americano Ronald Dworkin (1931-2013), a justiça igualitária será garantida apenas quando os recursos forem distribuídos de forma igual, sem que haja dependência de critérios subjetivos de bem-estar. Assim como Rawls, ele criticará as teorias que possuem como ideal o bem-estar. Haja vista que, para a promoção deste, seria necessário que toda a população informasse ao governo a sua condição, e ele teria que considerar como importante o que cada pessoa traça para si como ideário de vida. Por conseguinte, isso seria impossível, pois não haveria como o Estado chegar a um consenso acerca das políticas sociais adequadas para assegurar a igualdade de bem-estar a todos os indivíduos. Segundo Dworkin: 
Suponhamos, por exemplo, que um homem razoavelmente abastado tenha alguns filhos, um dos quais é cego, outro é um playboy com preferências dispendiosas, um terceiro tem pretensões políticas com aspirações dispendiosas, outro é um poeta com necessidades humildes, outro é um escultor que trabalha com material caro etc. Como ele deve elaborar seu testamento? (DWORKIN, 2012, p. 5).

De acordo com a teoria igualitária de justiça de Dworkin, no contexto de um Estado democrático de Direito, a igualdade deve sempre prevalecer em relação à liberdade, uma vez que é a virtude cardinal presente na comunidade política. Dada sua importância, a igualdade de recurso surge como faceta para a justiça distributiva compatível com uma sociedade baseada em um princípio político de igual consideração de todos os seus membros. Nesse sentido, Dworkin se assemelha ao pensamento rawlsiano, porém Dworkin partirá do pressuposto de que deve existir a igualdade de qualquer recurso. Caberá ao Estado a função da igualdade no tratamento de seus cidadãos, sendo que há duas formas de entender o direito à igualdade. (i.) O direito a um tratamento igual ou (ii.) o direito ao tratamento como igual ${ }^{2}$. $\mathrm{O}$ tratamento igual $(i$.) consiste no direito a uma distribuição igualitária de oportunidade, recursos e encargo (e.g., o direito ao voto ou à educação básica), ao passo que o segundo (ii.) se configura pelo direito de todos os cidadãos serem tratados com igual consideração e atenção, sendo este um direito inalienável e fundamental. A igualdade de recursos proposta por Dworkin ocorrerá na prática através da justiça distributiva. Para ilustrar tal relação, Dworkin se vale da ideia de leilão igualitário.

Na obra Sovereign Virtue, Dworkin expõe o chamado leilão igualitário, propondo que imaginemos um leilão que seja "sensível à dotação", mas não "sensível à ambição". Para isso, Dworkin nos propõe a análise de uma situação hipotética. Imaginemos que náufragos cheguem em uma ilha nunca anteriormente habitada e que resolvam fazer a divisão dos recursos disponíveis no local, ou seja, a distribuição de todos os recursos disponíveis na sociedade. Essa divisão ocorre por meio de um leilão, no qual todos os participantes recebem um número igual de conchas (100 conchas) para dar os lances pelos recursos que melhor se ajustam a seus planos de vida.

O leilão será exitoso se cada indivíduo ficar feliz com o seu pacote adquirido e, assim, não desejar o pacote do outro. Entra em cena o "teste de cobiça" para verificar se alguém

\footnotetext{
${ }^{2}$ Dworkin (2012, p. IX) afirma que a igual consideração e respeito devem ser exigidos da comunidade política, sendo a igualdade de fato a verdadeira virtude soberana da comunidade. De acordo com o filósofo: "Podemos dar as costas à igualdade? Nenhum governo é legítimo a menos que demonstre igual consideração pelo destino de todos os cidadãos sobre os quais afirme seu domínio e aos quais reivindique fidelidade. A consideração igualitária é a virtude soberana da comunidade política - sem ela o governo não passa de tirania.
} 
Artigo: Teorias da justiça pós-Rawls: uma análise comparada entre o modelo igualitário de Ronald Dworkin e Amartya Sen

cobiçará os recursos do outro. Segundo Dworkin, a distribuição dos recursos somente passará pelo teste de cobiça quando:

Ninguém cobiçar as compras de ninguém porque, hipoteticamente, poderia ter comprado tal porção com suas conchas, em vez da porção que comprou (...) o verdadeiro conjunto de porções tem o mérito de fazer com que cada pessoa desempenhe, por intermédio de suas compras com um estoque inicial igualitário de fichas, um papel igualitário que determina o conjunto de porções realmente escolhido. (DWORKIN, 2012, p. 84).

O teste de cobiça revela o aspecto igualitário da teoria de Dworkin, no qual todos partem do mesmo quinhão para realizar as suas escolhas ao longo da vida. O que importa na teoria dworkiniana é que todos tenham igualdade de ponto de partida, ou seja, que todos tenham os mesmos recursos para competir e realizar as suas escolhas futuras. O Estado assume, por sua vez, uma posição neutra em relação às escolhas individuais após a divisão igualitária dos recursos ${ }^{3}$. Tal proposta igualitária demonstra ser um esquema muito mais justo do que aquele empreendido por Rawls. De acordo com Cohen (2007, p. 933; Apud FERRAZ, p. 245) "Dworkin na realidade prestou um serviço considerável ao igualitarismo ao incorporar a ideia mais poderosa do arsenal da direita anti-igualitária: a ideia da escolha e da responsabilidade". Isso porque, após o sujeito realizar a escolha de seu quinhão, tendo em vista seu projeto de vida, ele arcará com a responsabilidade de suas escolhas naquele momento, bem como posteriormente. Para Kymlicka, a visão igualitária de Dworkin assume a sua forma mais defensável quando adota o "teste de cobiça". Segundo ele:

Tal esquema distributivo seria justo, embora permitisse certa desigualdade de renda. O horticultor e o tenista têm rendas desiguais, mas não há nenhuma desigualdade quanto ao respeito e interesse, já que cada um deles pode viver a vida que escolher, cada um tem igual capacidade de fazer lances por este pacote de bens sociais que servem melhor suas crenças a respeito do que dá valor à vida. (KYMLICKA, 2006, p. 100).

É para resolver possíveis conflitos em relação ao processo de divisão dos recursos que o teste de inveja é utilizado para aferir o leilão, ou seja, a divisão é feita a partir do que cada pessoa considera ser o melhor quinhão para si. Entretanto, esse teste só será satisfatório se

\footnotetext{
${ }^{3}$ Nesse sentido, Vita (2007, p. 65) afirma que "ou bem se considera que, se a justiça requer igualdade de recursos no ponto inicial, ela também exigirá essa igualdade em momentos subsequentes, ou bem se acredita que, se o laissez-faire é justificado para momentos posteriores, ele também o será para o ponto inicial [...]. A teoria de Dworkin fica com a primeira das duas alternativas acima: se há razões de justiça que requerem a neutralização de contingências moralmente arbitrárias na situação inicial, essas razões continuam tendo peso em momentos posteriores, quando os participantes do leilão hipotético fazem uso dos recursos que obtiveram".
} 
partirmos do princípio de que ninguém possui desvantagens em termos de bens naturais, ou seja, não envolve a distribuição de talentos, genes ou qualquer atributo natural. Assim, ao mesmo tempo em que o leilão é falho ao distribuir os recursos da sociedade ao não considerar as desvantagens naturais, ele, de per si, não será suficiente para evitar o sentimento de inveja e injustiça, haja vista que aqueles com tais desvantagens cobiçarão aquilo que é conquistado pelos outros que não possuem essa desvantagem. Assim, para solucionar esse problema e garantir a igualdade no ponto de partida e durante o desenvolvimento do mercado, o filósofo lança mão da ideia do seguro, que se desdobrará na ideia de compensação e tributação que visam a combater as diferenças naturais, bem como os possíveis problemas de economia de mercado ${ }^{4}$.

Antes de adentrarmos nas questões referentes ao seguro proposto por Dworkin, o que será um grande avanço em relação à teoria ralwsiana, faz-se necessário traçar uma distinção entre as formas de sorte. Para Dworkin, há duas formas de sorte: a sorte bruta e a sorte por opção ${ }^{5}$. Na sorte bruta as desigualdades naturais a que todos estão submetidos não pertencem à seara de nossas escolhas como, por exemplo, o fato de nascer numa família bem estruturada financeiramente ou não, ter habilidade para os esportes, para as artes ou ser um imbecil. Por outro lado, a sorte por opção é aquela relacionada às nossas escolhas, sendo deliberações nas quais podemos ou não ter sucesso. A sorte bruta é muito próxima ao conceito de loteria natural de Rawls. Todavia, ao adotar o elemento da sorte por opção, Dworkin ultrapassa o pensamento rawlsiano que não levava em conta as "circunstâncias que devem ser consideradas irrelevantes de um ponto de vista moral daquelas escolhas pelas quais os indivíduos devem ser responsabilizados" (GARGARELLA, 2008, p. XXI).

Para solucionar os problemas tanto da sorte bruta, quanto da sorte por opção, há o recurso ao seguro hipotético. Tal dispositivo é uma forma de minimizar os resultados das

\footnotetext{
${ }^{4}$ A igualdade de recurso está inserida na ideia de mercado econômico como núcleo dessa distribuição. Nesse sentido, Dworkin (1999, p. 355) afirma que "deveríamos, portanto, buscar um sistema de responsabilidade diferente, que também recomende o comportamento de simulação de mercado quando os direitos abstratos entrarem em conflito, mas que não pressuponha nenhum dever pessoal de agir sempre de algum modo que torne a comunidade mais feliz como um todo. Até aqui admitimos que, como o comportamento de simulação de mercado minimiza os prejuízos financeiros entre as pessoas afetadas por alguma conduta, aumentando assim a riqueza da comunidade como um todo, é preciso exigir que seja posto em prática em tais circunstâncias".

${ }^{5}$ Acerca da sorte, Vita (2008) afirma que "poderíamos pensar que o fator "sorte" [...] também tem um peso nãonegligenciável na produção das desigualdades. Mas, do ponto de vista normativo, parece mais relevante considerar adversidades repentinas (quando a sorte é madrasta) varia segundo quinhões distributivos de cada um. Ao passo que um golpe de azar (uma doença, a morte de um provador, a perda do emprego) pode obrigar uma família privilegiada a fazer ajustes em seu padrão de vida, uma adversidade similar pode fazer uma família pobre ser reduzida à penúria extrema".
} 
Artigo: Teorias da justiça pós-Rawls: uma análise comparada entre o modelo igualitário de Ronald Dworkin e Amartya Sen

escolhas e apostas realizadas na execução do plano de vida individual ${ }^{6}$. "A proposta de Dworkin é similar à ideia de Rawls de posição original. Devemos imaginar pessoas por trás de um véu de ignorância modificado" (KYMLICKA, 2006, p. 103), quer dizer, as pessoas, antes da realização do leilão, não sabem seu lugar na distribuição dos talentos naturais e devem supor que são suscetíveis a diversas desvantagens naturais. A partir de então, é dado um quinhão para cada pessoa e, posteriormente, é solicitada quanto que cada um estaria disposto a contribuir caso ele venha a ter algum tipo de desvantagem natural ou algum desfavorecimento posterior à distribuição. Cada valor do pacote cobre certo nível de desvantagens. Assim, a aquisição do seguro nesse mercado hipotético faz com que sejam diminuídas as desigualdades surgidas posteriormente ao leilão (ver CLAYTON, 2002, p. 8).

Dworkin propõe que, após as redistribuições do leilão e a prática do seguro acordado anteriormente, pensássemos na perpetuação do seguro por meio de um "sistema tributário para duplicar os resultados" (KYMLICKA, 2006, p. 103), ou seja, um imposto capaz de recolher "prêmios" que as pessoas pagariam com o intuito de garantir bem estar social, assistência à saúde e contra o desemprego (ver PARIJS, 2004, p. 52). Esses prêmios obtidos através do imposto de renda são necessários, pois, após o leilão inicial, dá-se o início da economia de mercado, juntamente com as produções, ocupações e atuações do comércio ${ }^{7}$. Para tanto, uma sociedade justa deve garantir a maior igualdade possível de recursos impessoais e pessoais, ou seja, os recursos passíveis de apropriação e transferência e as qualidades da mente e do corpo que são preponderantes para o êxito da realização dos projetos individuais.

Através desse esquema, Dworkin soluciona a insuficiência da concepção rawlsiana que não considerava as situações, nas quais os indivíduos não escolheram estar (sorte bruta), bem como não tornava esses responsáveis por suas escolhas (sorte por opção). Proporcionando, assim, mais igualdade diante das circunstâncias reais. Diante disso, Dworkin

\footnotetext{
${ }^{6}$ De acordo com Dworkin (2012, p.92): “já resolvemos que as pessoas devem pagar o preço da vida que decidiram levar, avaliado naquilo de que as outras pessoas abrem mão para que possam viver como escolheram. Essa era a finalidade do leilão como dispositivo para estabelecer a igualdade inicial de recursos".

7 Ao trabalhar na problemática da tributação posterior à redistribuição dos recursos, Dworkin (2012, p.115) afirma que, "nossa análise do problema que os talentos diferenciais apresentam à igualdade de recursos requer um imposto de renda, e não um imposto sobre a riqueza ou o consumo. Se as pessoas começam com recursos iguais, queremos então tributar para haver ajuste entre as habilidades diversas, na medida em que estas produzam rendas diferentes, pois é só assim que ameaçam a igualdade de recursos. A decisão de alguém de gastar em vez de poupar o que ganhou é precisamente o tipo de decisão cujas consequências devem ser definidas pelo mercado não corrigido para o imposto nesta análise".
} 
defenderá a prática de um modelo igualitário, com vistas à promoção de condições e recursos iguais para todos os cidadãos.

\section{A IGUALDADE DE CAPACIDADES DE AMARTYA SEN}

O economista e filósofo indiano Amartya Sen (1933) será um grande crítico de John Rawls. Na obra The idea of Justice, ele afirma que a proposta rawlsiana é apenas uma teoria transcendental, pois não lida com os problemas concretos da sociedade. Nesse sentido, os bens primários rawlsianos seriam insuficientes, pois não considerariam as diferentes circunstâncias e contextos, nos quais cada indivíduo está inserido. Diante desses limites, Sen buscará aprimorar a ideia de justiça ralwsiana, ampliando as igualdades necessárias para a vida dos indivíduos na sociedade.

A teoria seniana aduz a substituição "da lista heterogênea de bens primários, com seu emprego proeminente de recursos (renda e riqueza) como indicadores de bem-estar, por uma lista de capacidades, e todas elas seriam então, empregadas para medir a qualidade de vida" (NUSSBAUM, 2013, p. 202). Com vistas a garantir essa qualidade de vida, seu modelo de justiça distributiva pauta-se nas capacidades de funcionamento (functionings) do indivíduo, ou seja, mais do que propiciar bens básicos, o sujeito deve ter a capacidade (capability) necessária para alcançar o que é desejado ${ }^{8}$. Segundo Vita (2008, p. 92), “o que Sen nos propõe não é propriamente uma teoria da justiça, mas uma concepção de justiça distributiva em sentido estrito", haja vista que a sua proposta não é uma segunda via em relação ao pensamento rawlsiano, mas "tributário das estruturas normativas e ideológicas da teoria de Rawls”. Em suma, é com base nas ideias de liberdade e funcionalidade que Sen engendra a teoria de igualdade de capacidades ${ }^{9}$.

Através do desenvolvimento econômico ${ }^{10}$ e da concepção de capacidade e liberdade, a teoria seniana irá requerer as funcionalidades. A funcionalidade é "a capacidade igual de

\footnotetext{
${ }^{8}$ Sen (2008, p. 81) critica a teoria de Rawls e Dworkin afirmando que as duas não são suficientes para lidar com o problema do igualitarismo no que concerne à igualdade de capacidades. Acerca disso o filósofo afirma: "[...] a abordagem da capacidade difere claramente e de modo crucial das abordagens mais tradicionais da avaliação individual e social, baseada em variáveis tais como bens primários (como nos sistemas de avaliação rawlsianos), recursos(como na análise social de Dworkin), ou renda real (como nas análises que focalizam o PIB,PNB, vetores de bens nomeados)".

${ }^{9}$ Sen $(2008$, p. 234) afirma que em sua teoria o termo: "Capacidade [Capability] não significa o mesmo que 'Capacidade' [ability] no sentido ordinário do termo, como quando se diz que 'A pessoa P é capaz de nadar' porque neste sentido, 'capacidade' não implica em 'oportunidade': P pode ser capaz de nadar mesmo sem ter a oportunidade de nadar".

${ }^{10}$ Segundo Putnam a ideia de desenvolvimento econômico em Sen possui um sentido mais amplo do que o
} 
Artigo: Teorias da justiça pós-Rawls: uma análise comparada entre o modelo igualitário de Ronald Dworkin e Amartya Sen

funcionar" (VITA, 2008, p. 98), ou seja, estar adequadamente vestido, nutrido, conseguir ler e compreender um texto, estar livre de epidemias, sendo capaz de participar da vida em comunidade poder participar de associações de moradores, partidos políticos, bem como ter desenvolvido o sentimento de autoestima e reconhecimento ${ }^{11}$.

Somente partindo dessas funcionalidades é que será proporcionada a igualdade de capacidade, isto é, a liberdade efetiva de escolha que, aliada às funcionalidades, proporcionarão a igual capacidade do indivíduo. As funcionalidades são os estados das pessoas, e as capacidades são as ações que as pessoas praticam para alcançar os funcionamentos, sendo um reflexo da liberdade para realizar uma funcionalidade, ou seja, um bem-estar. Para Sem (2011, p. 268), a "capacidade está particularmente interessada em transferir esse foco sobre os meios para a oportunidade de satisfazer os fins e a liberdade substantiva para realizar esses fins arrazoados".

A capacidade refere-se à habilidade do indivíduo de realizar atos que são importantes e valiosos para ele próprio, ou seja, ações que proporcionam o seu florescimento humano. Dessa maneira, as capacidades são combinações de estados físicos e mentais que uma pessoa é capaz de ser ou fazer" ${ }^{12}$, sendo "um conjunto de vetores de funcionamentos, refletindo a liberdade da pessoa para levar um tipo de vida ou outro" (SEN, 2008, p. 80), representando as várias combinações de funcionamento que uma pessoa pode realizar. Em outras palavras, as capacidades não são apenas oportunidades ou "funcionalidades valiosas, elas são as liberdades de usufruir as funcionalidades valiosas" (PUTNAM, 2008, p. 85) para o alcance de determinado projeto de vida. O problema para Sen é centrado no fato de que os indivíduos são diferentes, pari passu, almejam e alcançam diferentes tipos de realizações e desenvolvimento.

comumente adotado, segundo ele, "a sabedoria convencional é que o único problema é aumentar a renda monetária ou, talvez, o rendimento econômico bruto das nações 'subdesenvolvidas'. Uma maneira pela qual Sen expõe a necessidade de medidas mais sensíveis de 'subdesenvolvimento', pobreza e outras formas de privação econômica é observando como são em si mesmas fracas as medidas de quantidade de dinheiro para o bem-estar econômico e do produto econômico bruto e como é seriamente limitada a 'base informacional', quando falhamos com obter informação sobre como os resultados flutuam, dados os níveis de renda ou produção, sob várias condições" (PUTNAM, 2008, p. 83). Para saber mais acerca das limitações das bases informacionais de renda e riqueza, confira o capítulo 4 da obra de Amartya Sen (2000).

11 Sen foi o criador de um dos indicadores da avaliação de desenvolvimento humano, segundo ele, "O desenvolvimento requer que se removam as principais fontes de privação de liberdade: pobreza e tirania, carência de oportunidades econômicas e destituição social sistemática, negligência de serviços públicos e intolerância ou interferência excessiva de Estados repressivos [...] Em outros casos, a privação de liberdade vincula-se estreitamente à carência de serviços públicos e assistência social, como por exemplo a ausência de programas epidemiológicos, de um sistema bem planejado de assistência médica e educação ou de instituições eficazes para a manutenção da paz e da ordem locais (SEN, 2000, p.18).

12 Para Nussbaum (2013, p. 202), essa capacidade frisa a "variabilidade da necessidade de recursos entre os indivíduos [...] e sua capacidade de converter esses recursos em funcionalidades", buscando proporcionar o real desenvolvimento individual e, por consequência, da comunidade. 
Essas diferenciações entre os seres humanos são tanto de tipos pessoais (sexo, idade, características físicas, psicológicas e mentais), quanto sociais (tais como riqueza, pobreza e responsabilidades herdadas) $)^{13}$. Esses fatores partem da loteria natural de Rawls e não podem ser negligenciados. A relação entre a igualdade e a liberdade que se dá por meio das funcionalidades será a responsável pelas oportunidades e capacidades que engendrarão as escolhas do indivíduo. De tal forma que a escolha social destes dependerá da vivência e da base informacional que a pessoa possui. Quanto a essa questão, Putnam afirma que a novidade introduzida por Sen seria que, "nos casos de privação extrema e duradoura, a satisfação dos desejos pode também ser uma base informacional empobrecida, porque uma consequência frequente desse tipo de privação é a redução no âmbito dos desejos, devido ao desespero da situação” (PUTNAM, 2008, p. 84).

Nesse sentido, “a necessidade de focar as capacidades fica especialmente clara quando consideramos os casos em que os indivíduos se encontram limitados de diversas formas atípicas em função da própria estrutura da sociedade" (NUSSBAUM, 2013, p 203), como no caso das sociedades que impediam negros de estudar e que, por isso, necessitarão de esforços extras para o letramento destes ${ }^{14}$. Segundo Sen,

\begin{abstract}
O desenvolvimento pode ser visto, argumenta-se aqui, como um processo de expansão das liberdades reais de que desfrutam as pessoas. Enfocar a liberdade humana contrasta com concepções mais estreitas do desenvolvimento, como as que o identificam com o crescimento do produto nacional bruto ou com o aumento da renda pessoal, ou com a industrialização, ou com o avanço tecnológico, ou com a modernização social. Ver o desenvolvimento em termos da expansão das liberdades substantivas dirige a atenção para os fins que tornam o desenvolvimento importante, antes que meramente para os meios, que, inter alia, cumprem parte proeminente no processo. (SEN, 2000, p. 03).
\end{abstract}

Como já aventado, Amartya Sen mesmo partindo da teoria igualitária de Rawls, defende que "a forma justa de responder à injustiça" (RAWLS, 2000, p. 245) é através do desenvolvimento das capacidades individuais. Nesse sentido, diminui o valor dado pela teoria rawlsiana às instituições sociais básicas, haja vista que, para a efetivação da justiça, mais do que ter acesso a esses bens, os indivíduos necessitam ter a real liberdade de escolha, que proporcionará o seu desenvolvimento.

\footnotetext{
${ }^{13}$ Segundo Gargarella (2008, p. 72), a teoria de Sen "é algo posterior à igualdade de bens primários e de recursos, mas é anterior à utilização de bens, como Sen exemplifica em relação ao nível nutricional de cada pessoa".

${ }^{14}$ Apenas com o intuito de ilustrar, podemos observer a exposição de Sen (ver 1999, p. 21).
} 
Artigo: Teorias da justiça pós-Rawls: uma análise comparada entre o modelo igualitário de Ronald Dworkin e Amartya Sen

Por fim, Sen tenta diminuir a sua crítica em relação ao pensamento rawlsiano, afirmando que, caso a motivação de Rawls ao engendrar os bens primários tenha sido com vistas à liberdade humana, "então eu diria que uma mudança de bens primários por capacidades não seria um afastamento fundamental do próprio programa de Rawls, mas sobretudo um ajuste na estratégia da razão prática" (SEN, 2011, p. 104). Nesse caso, a diferença entre o modelo seniano e o rawlsiano consistiria no procedimento para se alcançar as liberdades individuais ${ }^{15}$. Enquanto Rawls apresenta uma elaboração de princípios, Sen busca garantir as liberdades reais, mesmo diante de diferentes circunstâncias.

\section{CONSIDERAÇÕES FINAIS}

Como vimos, o modelo igualitário de Ronald Dworkin e Amartya Sen parte da ideia de justiça de Rawls, isto é, a proposta de igualdade baseada na satisfação de necessidades básicas e bens primários. Entretanto, cada um lidou de maneira diferente ao embasar métodos diferenciados para alcançar essa justiça, bem como o tipo de igualdade que se requer.

Por um lado, Dworkin parte da ideia que todos devem ter acesso aos mesmos recursos na posição inicial através do leilão igualitário. Por meio de um sistema articulado de impostos, o indivíduo poderia, na situação pós-leilão, se valer de outros benefícios. Por outro, Sen foca, não apenas na igualdade material de ponto de partida, mas na igualdade de capacidades que proporcionaria aquilo que as instituições básicas não proporcionam, que são as funcionalidades e a condição real de efetivação do projeto de vida do sujeito. Nesse sentido, a igualdade de oportunidades e escolhas envolveria não somente a disponibilidade de recursos, mas o acesso das pessoas a esses recursos que dependerão das habilidades individuais, uma vez que esses talentos são considerados, por Sen como limitantes da liberdade substantiva de ter e fazer escolhas e, por conseguinte, lutar por seus desejos.

Diante de tudo isso, foi possível interpretar as teorias de Dworkin e Sen como tentativas de melhoramento da teoria ralwsiana, buscando torná-la mais igualitária e dissolver possíveis imprecisões da teoria da justiça de Rawls. Somente partindo desses

\footnotetext{
${ }^{15}$ Para Sem (1993, p. 323), “As motivações subjacentes à teoria de Rawls e ao enfoque da capacidade são similares, mas o tratamento da questão é diferente. O problema com respeito ao argumento rawlsiano está em que, mesmo tendo - se em vista os mesmos fins, a capacidade que as pessoas têm de converter bens primários em realizações é diferente, de tal maneira que uma comparação interpessoal baseada na disponibilidade de bens primários em geral não tem como refletir também as liberdades reais de cada pessoa para perseguir um dado objetivo, ou objetivos variáveis".
} 
aperfeiçoamentos, os dois filósofos políticos acreditam poder satisfazer a proposta inicial igualitária engendrada pelo pensamento rawlsiano.

\section{REFERÊECIAS}

COHEN, G. On decurrancy of equalitariam justice. Ethics. Chicago: University of Chicago Press, 2007.

CLAYTON, Matthew. Liberal Equality and Ethics. Ethics. v. 113, n. 1, out. 2002, p. 8-22.

DWORKIN. Ronald. A virtude soberana: a teoria e a prática da igualdade. São Paulo: Martins Fontes, 2012.

DWORKIN. Ronald. Sovereign virtue: the Theory and Practice of Equality. London: Harvard University Press, 2002.

DWORKIN. Ronald. O império do direito. São Paulo: Martins Fontes, 1999.

FERRAZ, Octávio Luiz Motta. Justiça distributiva para cigarras e formigas. Novos Estudos, 2007. p. 243-253.

FLEISCHACKER, Samuel. A short history of justice distributive. Cambridge: Harvard University Press, 2004.

FOLLESDAL, Andreas. John Rawls (1921-2002). Giant on the Shoulders of Giants.

Diacrítica, Filosofia e Cultura, Braga (Universidade do Minho), n. 17/2, p. 285-290, 2003.

GARGARELLA, Roberto. As teorias da justiça depois de Rawls: um breve manual de filosofia política. São Paulo: Martins Fontes, 2008.

GUEST, Stephen. Ronald Dworkin. Edinburg: Edinburg University Press, 2010.

KYMLICKA, Will. Filosofia política contemporânea: uma introdução. São Paulo: Martins Fontes, 2006.

NUSSBAUM, Martha C. Fronteiras da justiça: deficiência, nacionalidade, pertencimento à espécie. São Paulo: WMF Martins Fontes, 2013.

PARIJS, Philippe Van. Equality of resources versus undominated diversity. Dworkin and his critics, 2004.

PUTNAM, Hilary. O colapso da verdade e outros ensaios. Aparecida: Ideias e letras, 2008.

RAWLS, John. A theory of justice. Revised Edition, Cambridge: Harvard University Press, 2000.

RAWLS, John. Collected papers. Ed. S. Freeman. Cambridge: Harvard University Press, 1999. 
Artigo: Teorias da justiça pós-Rawls: uma análise comparada entre o modelo igualitário de Ronald Dworkin e Amartya Sen

RAWLS, John. Justiça como Equidade: uma reformulação. Tradução de Cláudia Berliner. São Paulo: Martins Fontes, 2003.

RAWLS, John. O liberalismo político. São Paulo: WMF Martins Fontes, 2011.

RAWLS, John. Uma teoria da justiça. São Paulo: Martins Fontes, 2002.

SEN, Amartya. A ideia de justiça. São Paulo: Companhia das letras. 2011.

SEN, Amartya. Desenvolvimento como liberdade. São Paulo: Companhia das Letras, 2000.

SEN, Amartya. Desigualdade reexaminada. Rio de Janeiro: Record, 2008.

SEN, Amartya. Developmente as freedom. New York: Anchor Books, 1999.

SEN, Amartya. O Desenvolvimento como Expansão de Capacidades. Lua Nova, $n^{\circ}$ 28/29. 1993. p. 313-333.

SEN, Amartya. The idea of justice. Cambridge: Belknap Harvard, 2009.

VITA, Álvaro de. A justiça igualitária e seus críticos. São Paulo: WMF Martins Fontes, 2007.

VITA, Álvaro de. O liberalismo igualitário: Sociedade democrática e justiça internacional. São Paulo: WMF Martins Fontes, 2008. 